\title{
Disostosis cleidocraneal a tres años de tratamiento ortopédico.
}

\author{
Cleidocraneal dysostosis at three years of orthopedic treatment.
}

\author{
Álvaro Peralta-Dzib,* Fátima Sansores-Ambrosio, ${ }^{\ddagger}$ Tania Loria-Mondragón, ${ }^{\S}$ Mirna Minaya-Sánchez, \\ Alejandro Casanova-Rosado," Juan Casanova-Rosado**
}

\section{RESUMEN}

Introducción: La disostosis cleidocraneal es un trastorno genético raro con patrón hereditario. Sus rasgos patognomónicos son la aplasia clavicular, fontanelas y suturas abiertas, múltiples anomalías dentales. Su origen se relaciona con alteraciones en el gen RUNX2, importante para la síntesis de CBFA1, que a su vez funciona como un conformador óseo y un diferenciador de osteoblastos. Caso clínico: Paciente de 11 años con características clínicas de CCD, se corroboran los antecedentes genéticos hereditarios y alteraciones dentales relacionados con disostosis cleidocraneal. Resultado: A tres años de tratamiento se observa mejor definición facial, la erupción de piezas permanentes retenidas y mejor función masticatoria. Conclusión: Mejorar la calidad de vida del paciente con tratamientos interceptivos y el conocimiento de las alteraciones causadas por el síndrome, así como el trabajo interdisciplinario.

Palabras clave: Disostosis cleidocraneal, RUNX2, CBFA1, ortopedia.

\section{INTRODUCCIÓN}

$\mathrm{L}$ a disostosis cleidocraneal es un síndrome clasificado como osteocondrodisplasia. ${ }^{1}$ Su patología se ubica en el gen RUNX2, el mecanismo general es un estado que origina haploinsuficiencia. ${ }^{2}$ Sus características clínicas más representativas incluyen retardo en cierre de suturas craneales, clavículas hipoplásicas o aplásicas y

* Estudiante de Pregrado en Odontología.

¥ Odontopediatra de práctica privada. Catedrática.

$\S$ Estudiante de Maestría en Ciencias Forenses.

Catedrática.

\| Periodoncista de práctica privada. Catedrática.

『 Endodoncista de práctica privada. Catedrático.

** Ortodoncista de práctica privada. Catedrático.

Universidad Autónoma de Campeche. Campeche, México.

Recibido: 15 Enero 2019.

Aceptado para publicación: 28 Enero 2020.
ABSTRACT

Introduction: Cleidocranial dysostosis is a rare genetic disorder with a hereditary pattern. Its pathognomonic features are clavicular aplasia, fontanelles and open sutures, multiple dental anomalies. Its origin is related to alterations in the RUNX2 gene, important for the synthesis of CBFA1, which in turn functions as a bone conformer and an osteoblast differentiator. Clinical case: Patient with eleven years old with clinical characteristics of CCD, hereditary genetic background, and dental alterations related to cleidocranial dysostosis are corroborated. Result: After three years of treatment, the facial definition is better, the eruption of permanent pieces retained and better chewing function. Conclusion: Improve the quality of life of the patient with interceptive treatments and the knowledge of the alterations caused by the syndrome, as well as the interdisciplinary work.

Keywords: Cleidocranial dysostosis, RUNX2, CBFA1, orthopedics. alteraciones dentales como supernumerarios, erupción retardada de dientes permanentes. La inteligencia es típicamente normal. ${ }^{3}$

\section{PRESENTACIÓN DEL CASO}

Paciente femenino de 11 años de edad de la Facultad de Odontología de la Universidad Autónoma de Campeche referido por el Hospital General de Especialidades, a la exploración clínica se observa dolicocefalia, perfil convexo, cara triangular, falta de desarrollo de macizo facial, hueso frontal aplanado y extendido, retrognatismo maxilar y mandibular (Figura 1). Características que coincidieron con el diagnóstico establecido por el Hospital General de Especialidades: «disostosis cleidocraneal».

En los antecedentes personales se indicó que al nacer presentaba un peso de tres y medio kilos y un tamaño pequeño, le realizaron estudios por posibles cardiopatías, dando como resultado negativo. En la elaboración de la ficha clínica se corrobora el rasgo hereditario del síndrome basado en la 
narrativa de la madre (Figura 2). En el examen intraoral se halló retraso en la erupción, estando presentes únicamente primeros molares superiores, incisivo central superior e incisivos centrales inferiores, lo que refiere una edad dental de seis años, y maxilares en forma de «V》 (Figuras 3 y 4).

Radiográficamente se corrobora la existencia de alteraciones dentales: órganos dentarios permanentes retenidos, supernumerarios, malposiciones intraalveolares y alteraciones morfológicas de órganos dentarios; en radiografía carpal se apreció que la falange del quinto dedo es muy corto en comparación a pacientes normales (Figura 5). En el examen de química sanguínea se manifiestan valores elevados de fosfatasa alcalina.

\section{Tratamiento}

Extracciones selectivas de órganos dentarios temporales y estimulación con alimentación fibrosa, a pesar de eso los órganos dentarios permanentes no erupcionaban, así que a los cinco meses de iniciado el tratamiento se le colocó una placa Hawley en el arco superior con tornillo de expansión con el fin de estimulación. El tratamiento continuó durante nueve meses con revisiones mensuales, la erupción de los órganos permanentes no ocurría y se observaba tejido fibroso gingival, se optó por realizar procedimientos de incisión liberatriz a los 14 meses, un mes más tarde las coronas dentales de órganos intervenidos estaban erupcionadas en su totalidad, se le colocaron

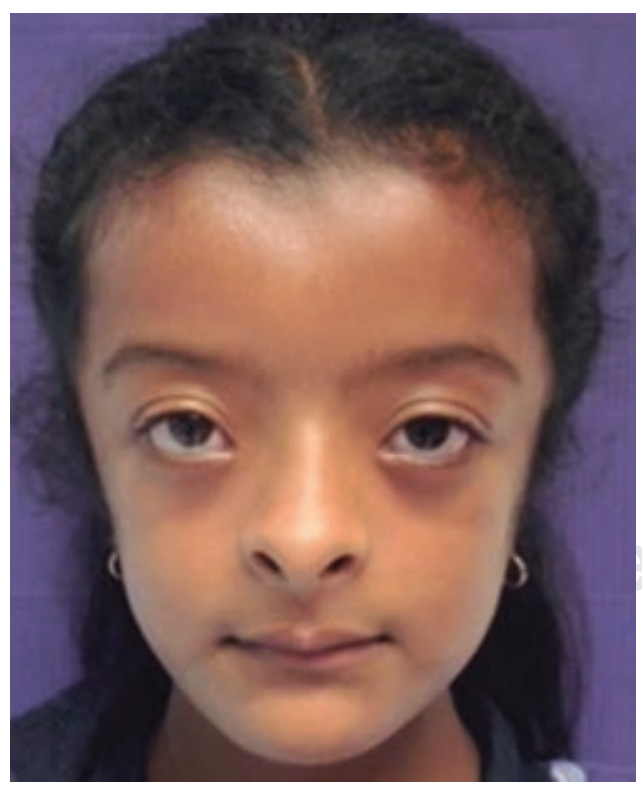

Figura 1: Fotografía frontal.

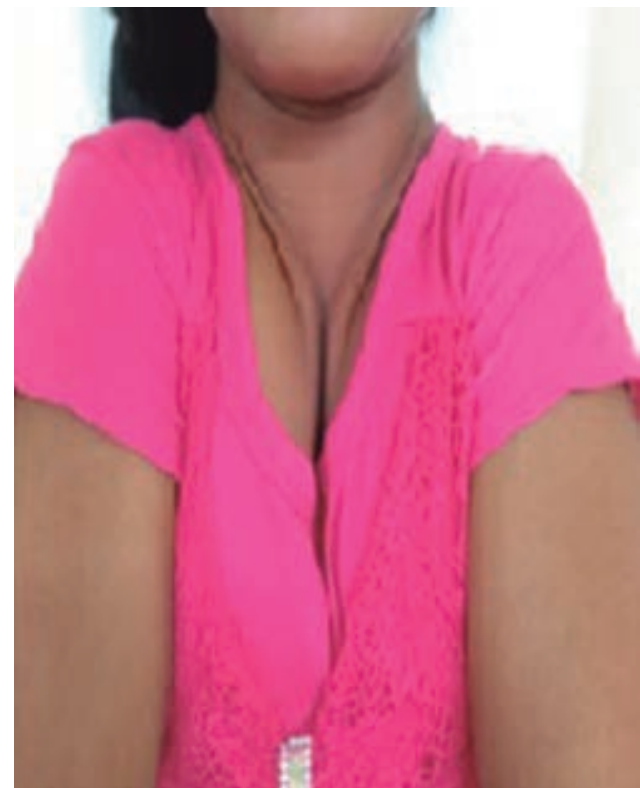

Figura 2: Hiperflexibilidad de hombros.

pistas planas superior e inferior. El tratamiento con pistas planas continúa hasta el momento de reportar estos resultados, con modificaciones como resortes para evitar rotaciones o lingualizaciones.

\section{Resultado}

Tres años después, con supervisión continua, se definen los maxilares con forma de «U», intraoralmente la erupción de 10 órganos dentarios permanentes y un mejor desarrollo del macizo facial (Figuras 6 a 8 ).

\section{DISCUSIÓN}

La disostosis cleidocraneal, también conocida como displasia cleidocraneal o síndrome de Marie y Sainton (CCD), es un trastorno genético con patrón hereditario. Su etiología se relaciona con el gen RUNX2 ubicado en el cromosoma 6 en el locus p21, pertenece a la familia de factores de transcripción RUNX y tiene un dominio Runt de unión a $\mathrm{ADN},{ }^{4}$ el gen regula el desarrollo óseo, la maduración ósea y el mantenimiento de los huesos a través de la regulación de la diferenciación y función de los osteoblastos. El estrógeno y la hormona paratiroidea (PTH) mejoran la expresión y la actividad de RUNX2 a través de los efectos anabólicos; sin embargo, el estrógeno regula negativamente el RUNX2 en la osteoclastogénesis. ${ }^{5}$ El gen codificará para una proteína llamada CBFA1, que 
es la encargada de la diferenciación de osteoblastos y conformación ósea.

Se ha reportado que esta proteína se expresa en tejidos orales, tales como la mesénquima del folículo dental, donde regula el crecimiento y la diferenciación, también es un factor clave para las interacciones entre la mesénquima epitelial y el control de la morfogénesis, así como para la histodiferenciación del órgano epitelial del esmalte, ${ }^{6}$ igualmente se expresa en ligamento periodontal, se ha demostrado que cuando existe la condición de disostosis cleidocraneal las células de este tejido muestran una capacidad reducida para inducir la diferenciación de osteoclastos activos, esto podría en parte, explicar la erupción dental retardada que se puede observar clínicamente. ${ }^{?}$

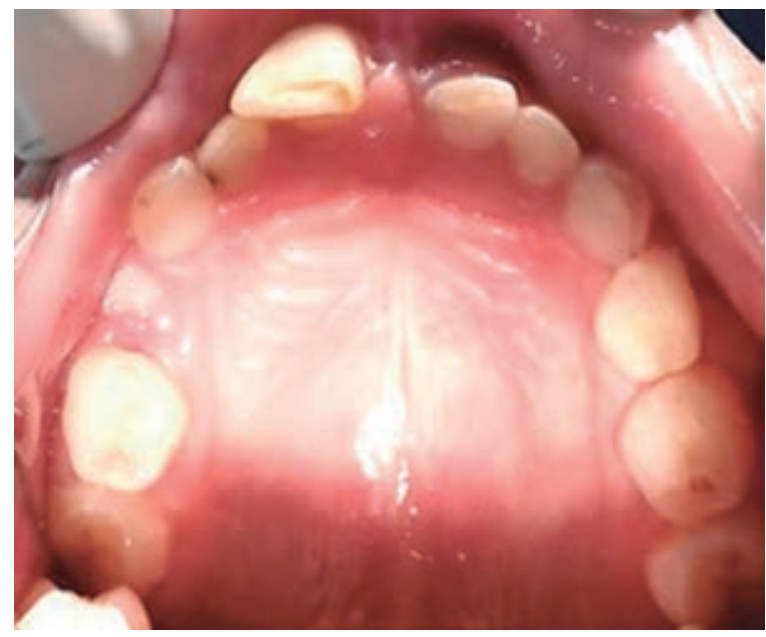

Figura 3: Fotografía oclusal superior.

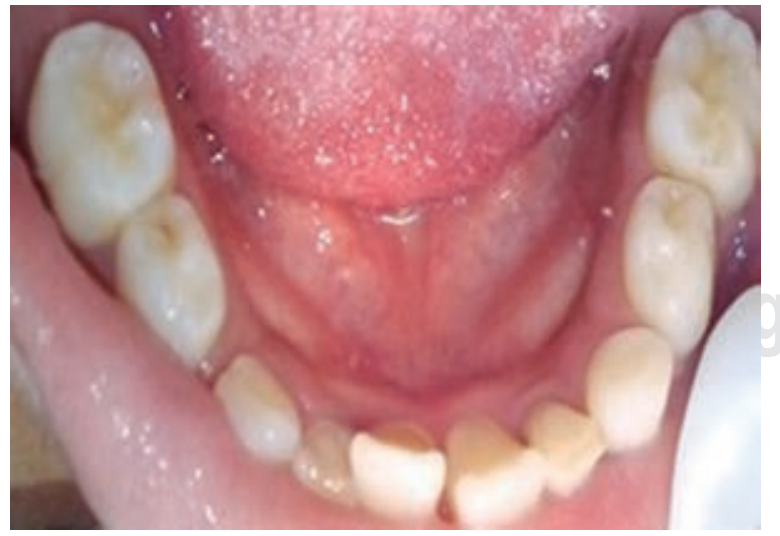

Figura 4: Fotografía oclusal inferior.

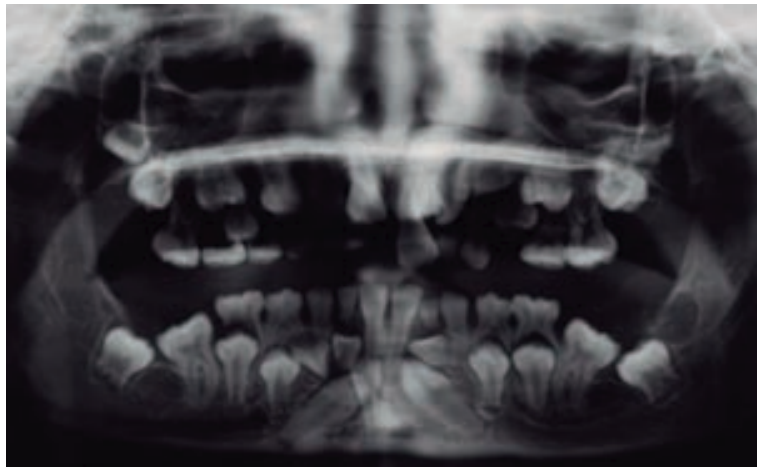

Figura 5: Ortopantomografía; se observan múltiples anomalías dentarias.

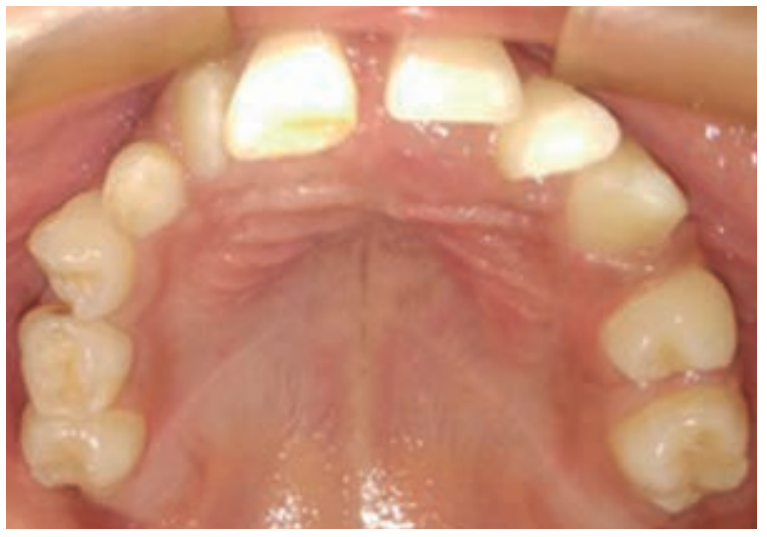

Figura 6: Oclusal superior postratamiento.

En su investigación, Mundlos describe tres posibles mecanismos biopatológicos del síndrome de acuerdo con sus estudios experimentales:

- Proteína no funcional: el gen afectado codifica adecuadamente la proteína, sin embargo, la misma no ejerce una función adecuada, entrando en un estado de haploinsuficiencia.

- Parada de síntesis antes de tiempo: el gen y la proteína codifica adecuadamente, por un mecanismo aún no esclarecido, la síntesis de la proteína se detiene antes de tiempo, lo que origina una deficiencia en la conformación ósea.

- Inexistencia total del gen. ${ }^{1}$

Su prevalencia es de 1/1,000,000. ${ }^{8}$ Históricamente se remonta su primer reporte aproximadamente en el año 1765 cuando oficialmente se hizo el primer reporte 
de aplasia clavicular, hacia 1871 Scheuthauer describe oficialmente sus características clínicas y en 1898 Marie y Sainton lo nombran «disostosis cleidocraneal hereditaria». ${ }^{9}$ Jackson en 1940 describe uno de los casos más importantes, denominado «caso Arnold», en su investigación elabora un mapa genealógico donde 70 descendientes de «Arnold» presentan los signos característicos del síndrome. ${ }^{10}$ En 1988 este síndrome entra en la categoría de displasia esqueletal de acuerdo con la clasificación de osteocondrodisplasias. En 1988 este síndrome se incorpora a la categoría de displasia esqueletal de acuerdo con la clasificación de osteocondrodisplasias, elaborada por Spranger. ${ }^{1}$ Ramesar en 1996 descubre que 100 pacientes de su muestra, comparten genes con un ancestro común que rastrea hasta el caso Arnold. ${ }^{11}$

El síndrome presenta múltiples signos clínicos como braquicefalia, frente amplia, hipoplasia del tercio medio facial, hombros caídos y estrechos, que clínicamente pueden llevarse a la línea media del cuerpo debido a la aplasia o hipoplasia clavicular, retraso en órganos de la segunda dentición, retención prolongada de dientes primarios, maloclusión. En la mano se puede observar braquidactilia. Un dato importante a resaltar es que el nivel intelectual no se ve afectado.

Radiográficamente se pueden hallar: suturas y fontanelas abiertas, retraso en osificación del cráneo, ausencia o deficiencia de senos paranasales y frontales, dientes impactados y supernumerarios. A la altura del tórax se puede observar escapula displásica, anomalías claviculares. En región pélvica un retraso en la osificación de hueso pélvico, hipoplasia de hueso iliaco, unión de sacros, coxa vara. En mano: hipoplasia de falanges distales, falanges medias cortas en tercero, cuarto y quinto dedo. En algunos casos puede presentar osteopenia. Pueden existir

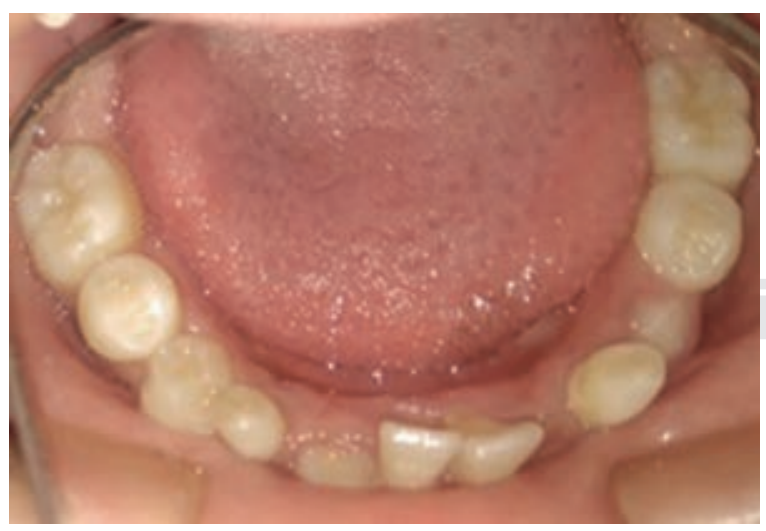

Figura 7: Oclusal inferior postratamiento.

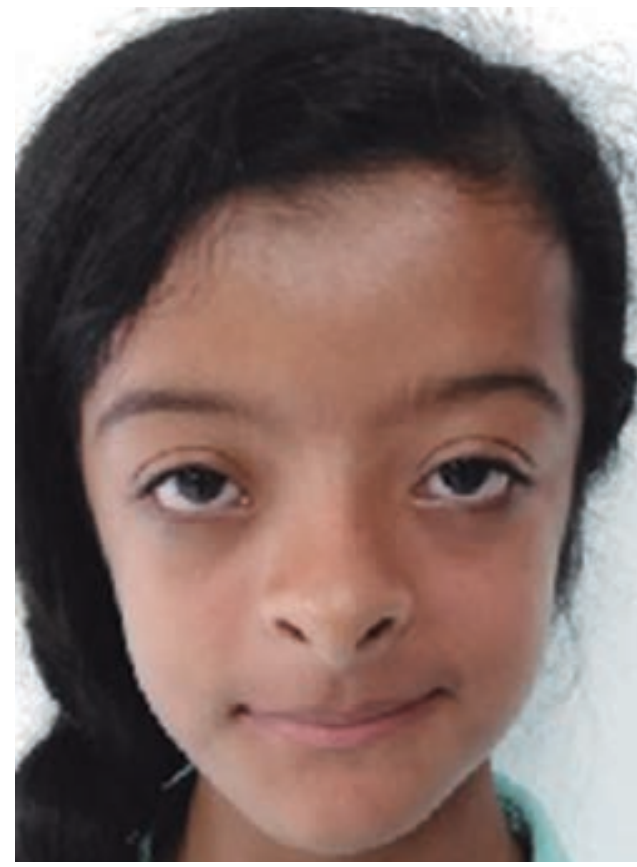

Figura 8: Frontal extraoral postratamiento.

complicaciones respiratorias como obstrucción de vías aéreas superiores, por lo que la intervención quirúrgica puede ser requerida, puede existir la pérdida de audición e infecciones auditivas frecuentes. Aproximadamente $57 \%$ de los pacientes pueden padecer osteoporosis y $21.4 \%$ osteopenia, así como niveles elevados de fosfatasa alcalina ${ }^{12,13}$ y complicaciones de desarrollo pequeño como baja estatura.

En 2018 Mehmet y colegas reportaron dos casos de disostosis cleidocraneal haciendo énfasis en deformidades espinales. ${ }^{14}$ Impellizzeri A. y su equipo reportaron en 2018 un caso en el que la madre y sus dos hijos presentaban el síndrome; uno de los hijos, de 12 años, sexo masculino, radiográficamente reveló una edad ósea de seis años, retraso de erupción dentaria, cinco supernumerarios, maloclusión, entre otros signos clínicos, el tratamiento consistió en aparatología ortodóntica acompañado de métodos quirúrgicos para eliminación de supernumerarios. El segundo hijo, paciente femenina de 17 años de edad, los hallazgos dentales indicaron dentición mixta, 11 supernumerarios, clase III molar y maloclusión, el tratamiento consistió en un enfoque de etapa quirúrgica única, similar al enfoque «Belfast-Hamburgo», posteriormente la fase ortodóncica. El caso restante, fue el de la madre de 44 años de 
edad, reportan que a los 30 años perdió la dentición primaria en su totalidad, intraoralmente hallaron en su total 11 supernumerarios, su tratamiento consistió en un dispositivo de ortodoncia fija, extracción de todos los supernumerarios y órganos dentarios impactados, alineación y tracción ortodóncica, preparándola para una posterior cirugía ortognática. ${ }^{15}$

En 2007 se realizó el reporte de un caso sobre una paciente con CCD de 12 años, que reveló la presencia de 12 supernumerarios, retención de órganos dentarios deciduos y erupción retardada de permanentes. Durante el transcurso del tratamiento ortodóntico se observó disminución en la sensibilidad auditiva, el autor recomienda realizar controles auditivos regulares, para evitar la pérdida de función. ${ }^{16}$ Roberts $T$, en su investigación reunió múltiples reportes de casos y enumeró las posibles opciones de tratamiento de acuerdo con la anomalía dental que presente el paciente, coincidiendo con tratamientos quirúrgicos, expansión con aparatología ortopédica y ortodóncica. ${ }^{17}$

\section{CONCLUSIONES}

Reconocer las características sindrómicas que afectan la cavidad oral son responsabilidad de los odontólogos, con tal de poder identificar e intervenir a tiempo en estas alteraciones. En el caso de CCD, la intervención temprana es importante, ya que la prioridad es mejorar la función masticatoria y estética de los pacientes. El tratamiento y la atención deberán ser llevados a cabo por un equipo interdisciplinario con el fin de mejorar la calidad de vida de los pacientes afectados.

\section{BIBLIOGRAFÍA}

1. Spranger J. Bone dysplasia 'families'. Pathol Immunopathol Res. 1988; 7: 76-80.

2. Mundlos S. Cleidocranial dysplasia: clinical and molecular genetics. J Med Genet. 1999; 36 (3): 177-182.

3. Machol K, Mendoza-Londono R, Lee B. Cleidocranial dysplasia spectrum disorder. 2006 Jan 3 [Updated 2017 Nov 16]. In: Adam MP, Ardinger HH, Pagon RA et al., editors. GeneReviews ${ }^{\circledR}$ [Internet]. Seattle (WA): University of Washington, Seattle; 1993-2018.
4. RUNX2 runt related transcription factor 2 [homo sapiens (human)]. Gene ID: 860, updated on 23-sep-2018. Available in: https://www. ncbi.nlm.nih.gov/gene?Db=gene \&Cmd=ShowDetailView\&TermToS earch $=860$

5. Komori T. Regulation of bone development and maintenance by Runx2. Front Biosci. 2008; 13: 898-903.

6. D'Souza R, Aberg T, Gaikwad J, Cavender A, Owen M, Karsenty $\mathrm{G}$ et al. Cbfa1 is required for epithelial-mesenchymal interactions regulating tooth development in mice. Development. 1999; 126 (13): 2911-2920. Available in: http://dev.biologists.org/content/ develop/126/13/2911.full.pdf

7. Lossdörfer S, Abou Jamra B, Rath-Deschner B et al. The role of periodontal ligament cells in delayed tooth eruption in patients with cleidocranial dysostosis. J Orofac Orthop. 2009; 70 (6): 495-510.

8. Stevenson DA, Carey JC, Byrne JL, Srisukhumbowornchai S, Feldkamp ML. Analysis of skeletal dysplasias in the Utah population. Am J Med Genet A. 2012; 158A (5): 1046-1054.

9. Marie P, Sainton P. On hereditary cleido-cranial dysostosis. Rev Neurol. 1898; 6: 835.

10. Jackson WP. Osteo-dental dysplasia (cleido-cranial dysostosis); the "Arnold head". Acta Med Scand. 1951; 139 (4): 292-307.

11. Ramesar RS, Greenberg J, Martin R et al. Mapping of the gene for cleidocranial dysplasia in the historical Cape Town (Arnold) kindred and evidence for locus homogeneity. J Med Genet. 1996; 33 (6): 511-514.

12. Golan I, Baumert U, Hrala BP, Müssig D. Dentomaxillofacial variability of cleidocranial dysplasia: clinicoradiological presentation and systematic review. Dentomaxillofac Radiol. 2003; 32 (6): 347-354.

13. Dinçsoy Bir F, Dinçkan N, Güven Y et al. Cleidocranial dysplasia: clinical, endocrinologic and molecular findings in 15 patients from 11 families. Eur J Med Genet. 2017; 60 (3): 163-168.

14. Balioğlu MB, Kargın D, Albayrak A, Atıcı Y. The treatment of cleidocranial dysostosis (Scheuthauer-Marie-Sainton Syndrome), a rare form of skeletal dysplasia, accompanied by spinal deformities: a review of the literature and two case reports. Case Rep Orthop. 2018; 2018: 4635761.

15. Impellizzeri A, Midulla G, Romeo U, La Monaca C, Barbato E, Galluccio G. Delayed eruption of permanent dentition and maxillary contraction in patients with cleidocranial dysplasia: review and report of a family. Int J Dent. 2018; 2018: 6591414.

16. Matthews-Brzozowska T, Hojan-Jezierska D, Loba W, Worona $M$, Matthews-Brzozowski A. Cleidocranial dysplasia-dental disorder treatment and audiology diagnosis. Open Med (Wars). 2018; 13: 1-8.

17. Roberts T, Stephen L, Beighton P. Cleidocranial dysplasia: a review of the dental, historical, and practical implications with an overview of the South African experience. Oral Surg Oral Med Oral Pathol Oral Radiol. 2013; 115 (1): 46-55.

Correspondencia:

Álvaro Daniel Peralta Dzib

Tel: +529811206995

E-mail: al039826@uacam.mx 